Article

\title{
A pH-Sensing Film from Tamarind Seed Polysaccharide with Litmus Lichen Extract as an Indicator
}

\author{
Tieqiang Liang ${ }^{1,2}$ and Lijuan Wang ${ }^{1,2, *}$ \\ 1 Key Laboratory of Bio-Based Materials Science and Technology of Ministry of Education, \\ Northeast Forestry University, Harbin 150040, China; ltq@nefu.edu.cn \\ 2 Research Center of Wood Bionic Intelligent Science, Northeast Forestry University, Harbin 150040, China \\ * Correspondence: donglinwlj@163.com; Tel.: +86-451-8219-1693
}

Received: 21 November 2017; Accepted: 20 December 2017; Published: 22 December 2017

\begin{abstract}
A new pH-sensing film was developed by using tamarind seed polysaccharide (TSP) and natural dye extracted from litmus lichen (LLE). The addition of LLE from 0 to $2.5 \%$ decreased the tensile strength and elongation at break from 30.20 to $29.97 \mathrm{MPa}$ and $69.73 \%$ to $60.13 \%$, respectively, but increased the water vapor permeability from $0.399 \times 10^{-9}$ to $0.434 \times 10^{-9} \mathrm{~g} \cdot \mathrm{s}^{-1} \cdot \mathrm{m}^{-1} \cdot \mathrm{Pa}^{-1}$. The UV-Vis spectra of the litmus lichen extract (LLE) in the $\mathrm{pH}$ range of 4-10 showed that the color clearly changed from orange to blue. The characterization results showed that TSP interacted with LLE through hydrogen bonds. The color of the film varied from orange ( $\mathrm{pH} 4.0)$ to blue-violet ( $\mathrm{pH}$ 10.0). The full cream milk spoilage test indicated that the film is suitable for application in full cream milk spoilage detection. The developed $\mathrm{pH}$-sensing film could be used as a promising diagnostic tool for the detection of food spoilage.
\end{abstract}

Keywords: tamarind seed polysaccharide; $\mathrm{pH}$ sensing; litmus lichen extract; packaging film

\section{Introduction}

To reduce white pollution, alternatives to synthetic polymer materials must be explored. In the past years, natural and biodegradable polymers such as chitosan, agar, pectin, and other different polymers have received extensive attention and have been applied as immobilization materials to prepare films [1-3]. Among those polymers, polysaccharides have been exploited and applied as immobilization materials owing to their good film-forming and oxygen barrier performances [4-6]. Tamarind seed polysaccharide (TSP) is a mucilaginous polysaccharide obtained from the seed kernels of Tamarindus indica Linn., which contains glucose, xylose, and galactose units at a ratio of 2.8:2.25:1 [7]. The structure of TSP is shown in Figure 1. It has been reported that TSP is nontoxic and can be used in the food industry [8]. In addition, it has also been employed as a drug-releasing material [9] and in textile printing fields [10]. However, to the best of our knowledge, the use of TSP in films has rarely been reported.

In a previous study, the development of fiber-optic and visual $\mathrm{pH}$ sensors was examined because of their compact size, safety, long-distance transmission, sensitivity, and low cost [11]. In the field of food safety, the microbial population and $\mathrm{pH}$ of foods have been reported to increase during the storage period owing to protein spoilage, indicating the relationship between the $\mathrm{pH}$ of foods and their freshness [12]. Therefore, $\mathrm{pH}$ sensing is useful for monitoring or indicating food freshness. Several studies have monitored the $\mathrm{pH}$ variations during chilled pork deterioration by using chitosan as an immobilization matrix $[13,14]$. In general, $\mathrm{pH}$-sensing chemical reagents such as bromocresol compounds, chlorophenol red, and cresol red have been widely used [15-17]. However, these synthetic chemical dyes may contaminate the food and pose a threat to human health owing to their potential 
toxicity [18]. Recently, several studies have reported the potential use of natural $\mathrm{pH}$-sensing dyes such as curcumin and anthocyanin, which are extracted from plants, in intelligent food packaging films $[2,12,19,20]$. Natural dyes have more obvious advantages, including nontoxicity, easy preparation, renewability, and a non-polluting nature [21]. Many centuries ago, litmus was obtained from lichens by treatment with urine or ammonia, and was widely used for dyeing silk and wool, along with alizarin and indigo. Sometimes, it was also used for dyeing foodstuffs [22]. However, the use of LLE (an extract of litmus lichen), as a pH indicator dye in film has not yet been studied.

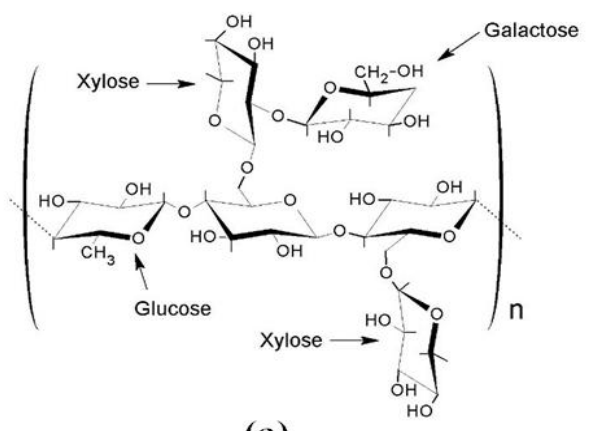

(a)

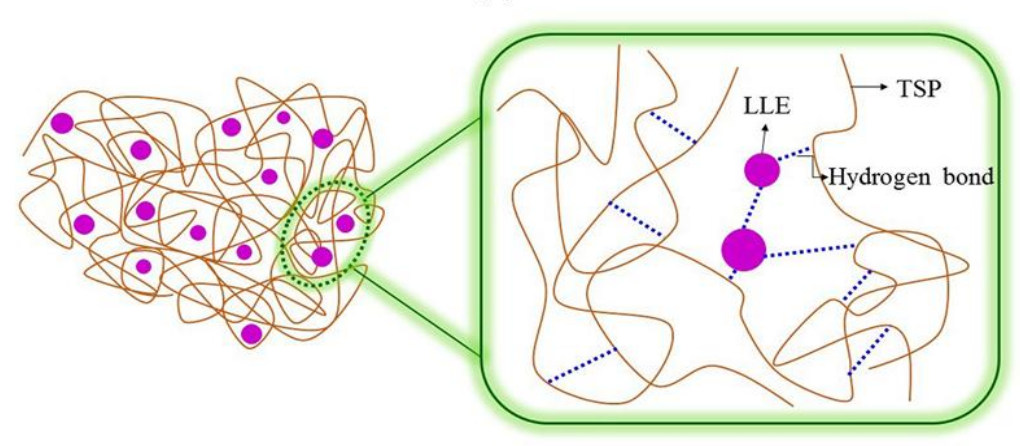

(b)

Figure 1. Structure of tamarind seed polysaccharide (TSP) (a) and schematic diagram of the TSP film after litmus lichen extract (LLE) addition (b).

In the present study, TSP was used to develop a novel film material, and LLE was used as a natural $\mathrm{pH}$ indicator dye, which were both natural biomaterials. The color change of the $\mathrm{pH}$-sensing film was sensitive and could be observed by the naked eye in the $\mathrm{pH}$ range of 4.0-10.0. The TSP/LLE films were analyzed by using Fourier transform-infrared spectroscopy (FTIR) and scanning electron microscopy (SEM). In addition, the mechanical properties and color response efficiency of the TSP/LLE films in different buffer solutions at various $\mathrm{pH}$ were also tested. Full cream milk was selected as the spoilage material to evaluate the potential use of this film in the food packaging industry, as it represents a mainstream milk product.

\section{Materials and Methods}

\subsection{Materials}

Litmus lichen was purchased from Macklin Biochemical Technology Co., Ltd. (Analytical Reagent, Shanghai, China). TSP was purchased from Shanghai AB Food and Beverages Ltd. (Shanghai, China). Anhydrous glycerin (analytical reagent) was purchased from Yongda Chemical Rregent Co., Ltd. (Tianjin, China). Fresh full cream milk was purchased from the milk industry (Harbin, China). 


\subsection{Experimental Procedures}

\subsubsection{Extraction Procedure}

According to the procedure of the "Pharmacopoeia of People's Republic of China" with some modifications [23], $0.5 \mathrm{~g}$ of litmus lichen powder was added to $200 \mathrm{~mL}$ of distilled water and incubated for $1 \mathrm{~h}$ at $80{ }^{\circ} \mathrm{C}$ with magnetic stirring. Then, the solutions were filtered by using $\mathrm{G}_{3}$ sintered discs to remove the solid and other non-hydrophilic materials. The concentration of the LLE solution was $1.49 \mathrm{~g} / \mathrm{L}$ obtained after the solution was dried to constant weight at $100^{\circ} \mathrm{C}$ in a weighted glass dish.

\subsubsection{Development of $\mathrm{pH}$-Sensing Films}

A total of $8 \mathrm{~g}$ of TSP powder were mixed with $200 \mathrm{~mL}$ of distilled water, and the mixture was heated to $90^{\circ} \mathrm{C}$ and maintained at this temperature for $2.5 \mathrm{~h}$ under constant stirring. The undissolved particles in the solution were removed by centrifugation at $5000 \mathrm{rpm}$ for $10 \mathrm{~min}$ [24]. Then, glycerol was added to the solution at a concentration of $35 \mathrm{~g} / 100 \mathrm{~g}$ TSP and stirred for $30 \mathrm{~min}$. Subsequently, LLE solution was added and the LLE content reached $1.25 \mathrm{~g} / 100 \mathrm{~g}$ and $2.5 \mathrm{~g} / 100 \mathrm{~g}$ (TSP basis), labeled as LLE-1.25 and LLE-2.5, respectively. In order to reduce the break to the structure of LLE and prevent the deterioration of TSP (according to our pre-experiment, a drying temperature below $80^{\circ} \mathrm{C}$ can cause the deterioration of TSP), the resulting solution was cast into a glass plate $(26 \mathrm{~cm} \times 26 \mathrm{~cm} \times 4 \mathrm{~cm})$ after removing bubbles and dried for $10 \mathrm{~h}$ at $80^{\circ} \mathrm{C}$ in a vacuum oven.

\subsection{Characterization}

\subsubsection{Mechanical Properties}

The thickness of the films was measured with an ID-C112XBS micrometer (Mitutoyo Corp., Tokyo, Japan), and recorded as the average of values measured at five random points. Tensile tests were performed using an auto tensile tester (XLW-PC, PARAM, Jinan, China) equipped with a $500 \mathrm{~N}$ load cell under a strain rate of $300 \mathrm{~mm} / \mathrm{min}$ at $25^{\circ} \mathrm{C}$ [25].

\subsubsection{Water Vapor Permeability}

The water vapor permeability (WVP) of the films was measured according to our previous study [6]. The cups, which contained anhydrous calcium chloride desiccant, were covered with the developed films. The mouths of the cups were sealed and the test assemblies were incubated at $25^{\circ} \mathrm{C}$ and $75 \%$ relative humidity (saturated $\mathrm{NaCl}$ solution). The driving force was $1753.55 \mathrm{~Pa}(\Delta P)$, which was expressed as water vapor partial pressure. The cups were weighed periodically to determine the amount of moisture transferred through the sample into the desiccant. WVP was realized in the steady state of the weight versus time result, and calculated by dividing the slope of the line by the exposed film area. Each film was tested in triplicate.

\subsubsection{UV-Vis Spectroscopy}

The UV-vis spectra of the LLE solutions were measured by using a UV-vis spectrophotometer (UV-2600, Shimadzu, Kyoto, Japan) at 400-700 nm. Before the measurement of the spectra of the LLE solutions ( $\mathrm{pH} 4.0-10.0$ ), the $\mathrm{pH}$ of the solutions were adjusted to the desired level by adding $0.1 \mathrm{M} \mathrm{HCl}$ or $\mathrm{NaOH}$.

\subsubsection{FTIR Spectroscopy}

FTIR analysis was performed using a Nicolet 6700 spectrometer (Thermo Fisher Scientific, Waltham, MA, USA), with an attenuated reflectance (ATR) Fourier transform mode. The FTIR spectra of the films were measured between 4000 and $500 \mathrm{~cm}^{-1}$ and recorded at a $4 \mathrm{~cm}^{-1}$ resolution. 


\subsubsection{SEM Observation}

Micrographs of the films were observed by using a Quanta 200 scanning electron microscope (Philips-FEI Co., Eindhoven, The Netherlands) under an accelerating voltage of $5 \mathrm{kV}$ after applying a thin gold layer onto the films prior to observation.

\subsubsection{Color Response Analysis}

The color changes of the $\mathrm{pH}$-sensing films were measured by using a colorimeter (CM-2600d, Konica Minolta, Tokyo, Japan). Before the measurement, the $\mathrm{pH}$-sensing films were immersed in $5 \mathrm{~mL}$ of each buffer solution at $\mathrm{pH} 4.0-10.0$ for $5 \mathrm{~s}$. After removing the buffer solutions, each film was placed on a white plate and its color was noted before drying. The results were expressed as $L^{*}$ (lightness), $a^{*}$ (red to green), and $b^{*}$ (yellow to blue) parameters to evaluate the color changes in different buffer solutions at various $\mathrm{pH}$ levels. All of the measurements were determined at three random points on both sides of each film, and the experiments were performed in triplicate.

\subsubsection{Application of the Developed Film in the Detection of Full Cream Milk Spoilage}

Full cream milk spoilage is related to its $\mathrm{pH}$, acidity, and microbial load, among which the acidity of the milk is the most important index [26]. In the present study, the acidity of milk was initially measured by the titration method (according to Chinese GB/T 5009.46-2003). In brief, $10 \mathrm{~mL}$ of milk and $20 \mathrm{~mL}$ of sterile purified water were titrated against $0.1 \mathrm{~mol} / \mathrm{L} \mathrm{NaOH}$ using alcoholic phenolphthalein as an indicator at $40^{\circ} \mathrm{C}$. An acidity between 16 and $18^{\circ} \mathrm{T}$ revealed that the milk was fresh, that between 18 and $20^{\circ} \mathrm{T}$ showed that the milk was suitable for consumption, and that beyond $20^{\circ} \mathrm{T}$ indicated that the milk was spoiled and could not be consumed. Meanwhile, the color changes of the $\mathrm{pH}$-sensing film in milk with different acidity levels were tested after the $\mathrm{pH}$-sensing film was immersed in $5 \mathrm{~mL}$ of milk with different acidity levels by using a colorimeter (CM-2600d, Konica Minolta, Tokyo, Japan).

\subsubsection{Statistical Analysis}

The data obtained were analyzed by analysis of variance using SPSS (version 17.0, SPSS Inc., Chicago, IL, USA). Duncan's multiple-range test $(p<0.05)$ was used to compare the differences between the films' properties.

\section{Results and Discussion}

\subsection{Mechanical Properties of the $\mathrm{pH}$-Sensing Films}

The thickness, tensile strength (TS), and elongation at break (EAB) of the TSP films with various concentrations of LLE are shown in Table 1. There was no significant change in the thickness of the films. However, with the increasing concentration of LLE up to $2.5 \%$, the TS and EAB of the films decreased from 30.20 to $29.97 \mathrm{MPa}$ and $69.74 \%$ to $60.13 \%$, respectively, owing to the decrease in intramolecular and intermolecular interaction between the TSP molecules and plasticizers, which are correlated to the LLE structure and composition. In particular, the EAB value significantly decreased. These results corresponded to those obtained in the FTIR analysis.

Table 1. Mechanical properties and water vapor permeability (WVP) values of the $\mathrm{pH}$-sensing film.

\begin{tabular}{|c|c|c|c|c|}
\hline Sample & Thickness (mm) & TS (MPa) & EAB (\%) & $\mathrm{WVP}\left(\mathrm{g} \cdot \mathrm{s}^{-1} \cdot \mathrm{m}^{-1} \cdot \mathrm{Pa}^{-1} \times 10^{-9}\right)$ \\
\hline TSP film & $0.082 \pm 0.011^{\mathrm{b}}$ & $30.20 \pm 2.62^{a}$ & $69.73 \pm 5.20^{a}$ & $0.399 \pm 0.061^{\mathrm{a}}$ \\
\hline LLE-1.25 & $0.077 \pm 0.003^{\mathrm{a}, \mathrm{b}}$ & $30.16 \pm 0.24^{\mathrm{a}}$ & $68.13 \pm 5.91^{\mathrm{a}}$ & $0.400 \pm 0.060^{\mathrm{a}}$ \\
\hline LLE-2.5 & $0.076 \pm 0.003^{\mathrm{a}}$ & $29.97 \pm 1.25^{\mathrm{a}}$ & $60.13 \pm 1.42^{\mathrm{a}}$ & $0.434 \pm 0.087^{b}$ \\
\hline
\end{tabular}




\subsection{WVP of the $\mathrm{pH}$-Sensing Films}

As shown in Table 1, the WVP of the $\mathrm{pH}$-sensing films gradually increased from $0.399 \times 10^{-9}$ to $0.434 \times 10^{-9} \mathrm{~g} \cdot \mathrm{s}^{-1} \cdot \mathrm{m}^{-1} \cdot \mathrm{Pa}^{-1}$ with the increase in the LLE content from 0 to $2.5 \mathrm{~g} / 100 \mathrm{~g}$ TSP, but the WVP values of films were still very low. The increase of WVP values may be owing to the fact that LLE is hydrophilic and the addition of LLE caused a decrease in the intramolecular and intermolecular interactions.

\subsection{UV-Vis Spectroscopy of LLE Solutions at Various $p H$ Ranges}

The color variations of the diluted LLE solutions were examined and recorded to validate its use as a $\mathrm{pH}$-sensing dye. The initial $\mathrm{pH}$ of the LLE solution was 10.0. Figure 2A shows that the color of the LLE solution changed from blue to purple, orange, and yellow when the $\mathrm{pH}$ was 10.0-9.0, 8.0-7.0, 6.0-5.0, and 4.0, respectively. In general, visible color absorbs light of wavelengths corresponding to its complementary color [20], and orange and blue are complementary colors [27]. The maximum absorption peak at 580 shifted to $576 \mathrm{~nm}$ when the $\mathrm{pH}$ decreased from 10.0 to 6.0 , and the strength of the peak also decreased. When the $\mathrm{pH}$ was $<6.0$, the peak disappeared, which resulted in the change in the color of the LLE solution from blue to orange. Moreover, the maximum absorption peak at 495 shifted to $580 \mathrm{~nm}$ when the $\mathrm{pH}$ increased from 4.0 to 10.0, and the strength of the peak at 495 decreased while the strength of the peak at 580 increased. The adsorption peaks around 495 and $580 \mathrm{~nm}$ were due to the presence of hydroxyorceins, and the 7-hydroxyphenoxazone chromophore was the principal constituent. The adsorption peak change was related to the change in chemical structure. In an acidic condition, a proton combined with the nitrogen atom in 7-hydroxyphenoxazone chromophore to obtain the red cation, while above $\mathrm{pH} 7,7$-hydroxyphenoxazone chromophore eliminated a proton to give the mesomeric to form a blue-violet anion; detail mechanism is shown in Figure 2C [22,28,29]. As a result, the absorption peak shifted to longer wavelengths with the $\mathrm{pH}$ increasing from 4.0 to 10.0 .

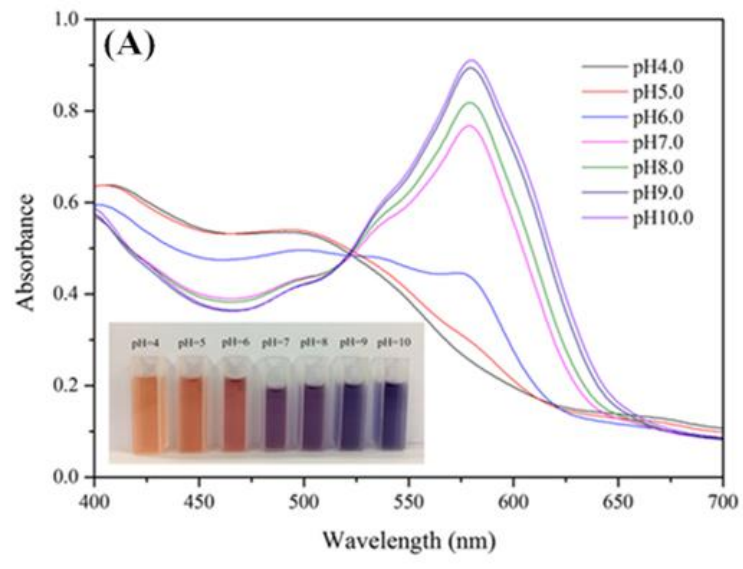

(C)

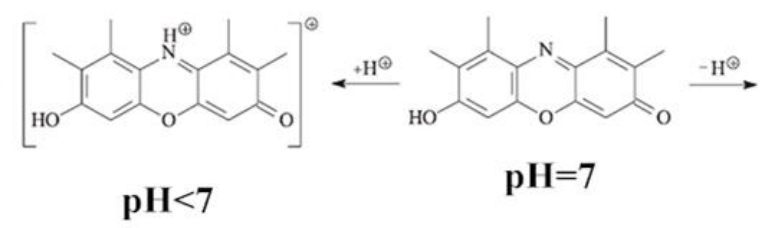

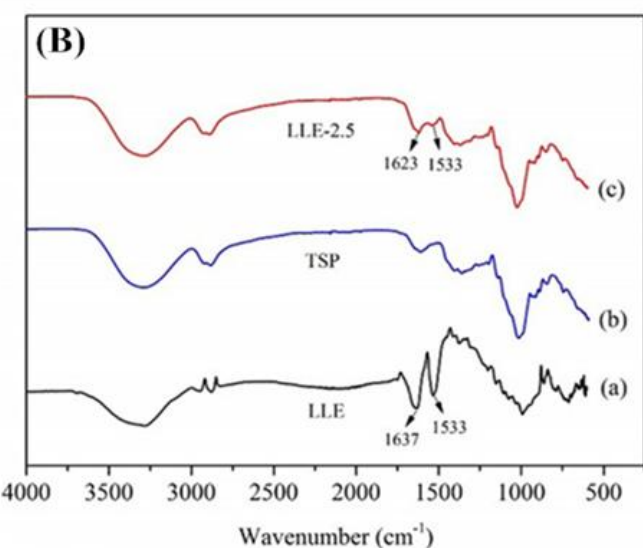

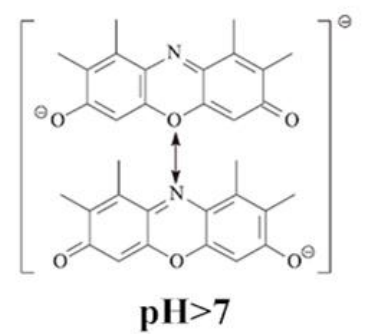

Figure 2. (A): UV-Vis spectra of the LLE at different $\mathrm{pH}$ values; (B): FTIR spectra of LLE (a), TSP film (b), and $\mathrm{pH}$-sensing film (c); (C): the detail mechanism of LLE at different $\mathrm{pH}$ levels [22]. 


\subsection{FTIR Spectra of the $p H$-Sensing Films}

The FTIR spectra of LLE, TSP film, and the $\mathrm{pH}$-sensing film (LLE-2.5) are shown in Figure 2B. As indicated in Figure 2Ba, the bands at around 3400, 1637, 1533, and $1000 \mathrm{~cm}^{-1}$ correspond to -OH stretching vibration, $\mathrm{C}=\mathrm{C}$ stretching vibration, $\mathrm{N}-\mathrm{H}$ bending vibration, and $\mathrm{C}-\mathrm{O}$ stretching vibration, respectively [30,31]. Furthermore, the bands at 2941 and $2879 \mathrm{~cm}^{-1}$ can be attributed to $-\mathrm{CH}$ in-plane deformation vibration. These comprehensive spectral patterns were noted to be in accordance with the appropriate results with featured molecular frames extracted from litmus lichen [22].

Figure $2 \mathrm{Bb}$ indicates that a broad band at around $3400-3200 \mathrm{~cm}^{-1}$ corresponds to $-\mathrm{OH}$ stretching vibrations [32]. The bands at 2940 and $2888 \mathrm{~cm}^{-1}$ can be attributed to the feature of glycerol, and the band at $1618 \mathrm{~cm}^{-1}$ corresponding to $\mathrm{N}-\mathrm{H}$ bending vibration may indicate the presence of residual proteins [33]. In particular, the bands at $1022,1153,1618,2888$, and $3300 \mathrm{~cm}^{-1}$ can be attributed to $-\mathrm{H}=\mathrm{C}$ stretching vibration, $-\mathrm{C}-\mathrm{O}-\mathrm{C}$ - asymmetric stretching vibration of glucopyranosyl and xylopyranosyl units, $-\mathrm{CH}-\mathrm{OH}$ stretching vibration, aliphatic $\mathrm{C}-\mathrm{H}$ stretching vibration, and $-\mathrm{OH}$ stretching vibration, respectively [34]. In addition, the bands at $930-730 \mathrm{~cm}^{-1}$ indicate the vibration of pyranose rings in polysaccharides [35].

As illustrated in Figure 2Bc, an increase in the intensity of band at $1623 \mathrm{~cm}^{-1}$ and a new band at $1533 \mathrm{~cm}^{-1}$ in the LLE $\mathrm{pH}$-sensing film spectrum could be attributed to the addition of LLE. Moreover, it can be noted that the bands at 1022 and $1618 \mathrm{~cm}^{-1}$ observed in Figure 2Bb moved to a higher wavelength (1027 and $1623 \mathrm{~cm}^{-1}$ ), suggesting that the addition of LLE reduced the interactions among TSP molecules in the film [36]. These results showed that LLE was immobilized onto the TSP film, and that the addition of LLE produced weak intermolecular interactions in the film. The concise structural model of the TSP film after LLE addition is shown in Figure 1.

\subsection{SEM Observation}

The micrographs of the surfaces and freeze-fractured cross-sections of the TSP film and $\mathrm{pH}$-sensing film (LLE-1.25 and LLE-2.5) are presented in Figure 3. In the absence of LLE, the surface of the TSP film was slightly rough, because TSP is a polyhedral structure [7]. The roughness of the film increased with the addition of LLE owing to the reduced intermolecular interactions between the TSP molecules.
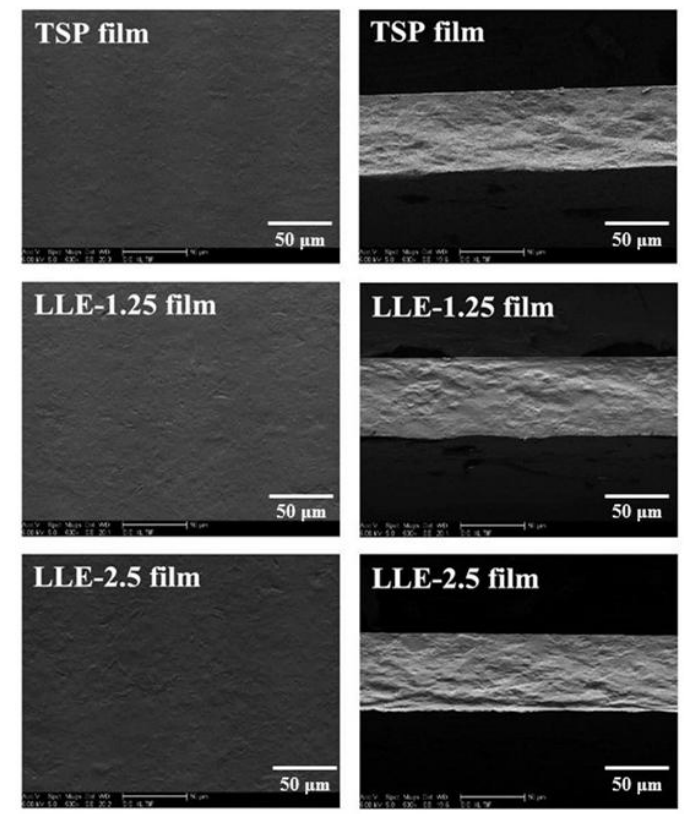

Figure 3. SEM of the TSP film and pH-sensing film (LLE-2.5). Left micrograph shows the surface of the film and right micrograph illustrates the cross-section of the film. 


\subsection{Color Response Analysis of the pH-Sensing Films}

According to the results of the pre-experiment, LLE-2.5 was selected for the color response test. The color response of the $\mathrm{pH}$-sensing film was evaluated by immersing the film into different buffer solutions ( $\mathrm{pH}$ 4.0-10.0) for $5 \mathrm{~s}$. Table 2 shows the visible color changes of each sample from orange to purple in different buffer solutions ( $\mathrm{pH} 4.0-10.0$ ). The values of $a^{*}$ and $b^{*}$ parameters were significant. With the decrease in the $a^{*}$ and $b^{*}$ values, the $\mathrm{pH}$-sensing film turned bright orange, fuchsia, purple, and blue-violet at $\mathrm{pH} 4.0,5.0-6.0,7.0-8.0$, and 9.0-10.0, respectively, indicating that the film is sensitive to $\mathrm{pH}$.

Table 2. Color parameters of the $\mathrm{pH}$-sensing film in different buffer solutions at $\mathrm{pH}$ 4.0-10.0.

\begin{tabular}{|c|c|c|c|c|}
\hline pH Value & $L^{*}$ & $a^{*}$ & $b^{*}$ & Pictures \\
\hline 4.0 & $64.39 \pm 0.47^{\mathrm{c}}$ & $15.45 \pm 0.26^{\mathrm{g}}$ & $8.22 \pm 0.28^{\mathrm{e}}$ & \\
\hline 5.0 & $61.87 \pm 0.78^{b}$ & $12.23 \pm 0.45^{\mathrm{f}}$ & $2.24 \pm 0.37^{\mathrm{d}}$ & \\
\hline 6.0 & $61.88 \pm 1.04^{b}$ & $9.66 \pm 0.38^{e}$ & $-1.27 \pm 0.70^{c}$ & \\
\hline 7.0 & $59.67 \pm 1.40^{a, b}$ & $5.48 \pm 0.29 \mathrm{~d}$ & $-6.37 \pm 0.23^{b}$ & \\
\hline 8.0 & $61.76 \pm 1.57^{\mathrm{a}, \mathrm{b}}$ & $4.06 \pm 0.21^{\mathrm{c}}$ & $-7.24 \pm 1.12^{a, b}$ & \\
\hline 9.0 & $59.59 \pm 1.53^{a}$ & $2.43 \pm 0.04^{\mathrm{a}}$ & $-7.45 \pm 0.03^{a}$ & \\
\hline 10.0 & $60.74 \pm 1.17^{\mathrm{a}, \mathrm{b}}$ & $3.11 \pm 0.17^{b}$ & $-8.11 \pm 0.11^{a}$ & \\
\hline
\end{tabular}

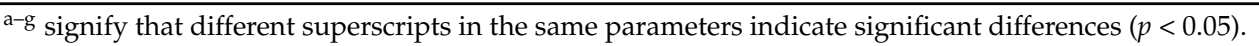

\subsection{Full Cream Milk Spoilage Detection by the $\mathrm{pH}$-Sensing Films}

To validate the reliability of the use of $\mathrm{pH}$-sensing films in practical applications, the acidity of milk was detected by using the $\mathrm{pH}$-sensing films (Table 3). The initial acidity of milk was $16.35^{\circ} \mathrm{T}$, which indicated that the milk was fresh. After $7 \mathrm{~h}$, the acidity increased to $18.03^{\circ} \mathrm{T}$, which suggested the start of milk spoilage. In $8 \mathrm{~h}$, the milk was significantly spoiled owing to the acute increase in lactic acid concentration, and the $\mathrm{pH}$ of the milk obviously changed. With regard to the color parameters, there was only a slight difference in the $L^{*}$ value, whereas the $a^{*}$ and $b^{*}$ values increased with the decreasing $\mathrm{pH}$ and increasing acidity, and the $\mathrm{pH}$-sensing films turned to red and yellow. After $8 \mathrm{~h}$, the color of the film turned from blue-violet to fuchsia, and after $10 \mathrm{~h}$, the film turned from blue-violet to orange, indicating that the milk was completely spoiled. These results showed that the $\mathrm{pH}$-sensing film could detect milk spoilage and can be used in practical applications. 
Table 3. Color parameters, $\mathrm{pH}$ value, and acidity of the $\mathrm{pH}$-sensing film immersed in milk at different time points.

\begin{tabular}{cccccc}
\hline \multirow{2}{*}{ Time (h) } & $\boldsymbol{L}^{*}$ & $\boldsymbol{a}^{*}$ & $\boldsymbol{b}^{*}$ & $\mathbf{p H}$ Value & $\begin{array}{c}\text { Acidity } \\
\left.\mathbf{(}^{\circ} \mathbf{T}\right)\end{array}$ \\
\hline 0 & $51.33 \pm 0.517^{\mathrm{a}}$ & $9.22 \pm 0.252^{\mathrm{a}}$ & $-4.13 \pm 0.229^{\mathrm{a}}$ & 6.78 & 16.35 \\
6 & $54.10 \pm 0.907^{\mathrm{a}}$ & $9.38 \pm 0.283^{\mathrm{a}}$ & $-3.64 \pm 0.092^{\mathrm{a}, \mathrm{b}}$ & 6.62 & 16.36 \\
7 & $55.03 \pm 1.175^{\mathrm{a}}$ & $10.04 \pm 0.670^{\mathrm{a}, \mathrm{b}}$ & $-3.38 \pm 0.303^{\mathrm{b}}$ & 6.54 & 18.03 \\
8 & $53.82 \pm 0.664^{\mathrm{a}}$ & $10.48 \pm 0.014^{\mathrm{b}, \mathrm{c}}$ & $-3.08 \pm 0.140^{\mathrm{b}}$ & 6.32 & 20.55 \\
9 & $50.92 \pm 0.573^{\mathrm{a}}$ & $11.21 \pm 0.417^{\mathrm{c}}$ & $-1.01 \pm 0.205^{\mathrm{c}}$ & 5.98 & 27.26 \\
10 & $54.11 \pm 2.833^{\mathrm{a}}$ & $11.35 \pm 0.295^{\mathrm{c}}$ & $-0.82 \pm 0.365^{\mathrm{c}}$ & 5.49 & 35.23 \\
\hline \multicolumn{7}{c}{ a-c signify that different superscripts in the same parameters indicate significant differences $(p<0.05)}$.
\end{tabular}

\section{Conclusions}

In this study, natural dye extracted from litmus lichen was used as a $\mathrm{pH}$ indicator, and a bio-based material, TSP, was employed to immobilize the natural dye to prepare a $\mathrm{pH}$-sensing film. The addition of LLE from 0 to $2.5 \%$ TSP decreased the TS and EAB from 30.20 to $29.97 \mathrm{MPa}$ and $69.73 \%$ to $60.13 \%$, respectively, while it increased the WVP from $0.399 \times 10^{-9}$ to $0.434 \times 10^{-9} \mathrm{~g} \cdot \mathrm{s}^{-1} \cdot \mathrm{m}^{-1} \cdot \mathrm{Pa}^{-1}$. The color of the film varied from yellow to blue in the $\mathrm{pH}$ range of 4.0-10.0. FTIR spectra indicated the presence of hydrogen bonds between the polymers. While the addition of LLE interrupted the intermolecular and intramolecular interactions, which decreased the TS and EAB of the TSP film, it enhanced the WVP, although the WVP values were still very low. The milk spoilage test showed that the $\mathrm{pH}$-sensing film could detect the spoilage of milk and can have practical applications. The developed $\mathrm{pH}$-sensing film exhibited good responses to $\mathrm{pH}$ change in solutions, which suggested its significant potential as an intelligent package material in the food industry to monitor the freshness of packaged foods. Further studies will be conducted to determine the correlation between the color of the $\mathrm{pH}$-sensing film and various foods to estimate the degree of spoilage of foods.

Acknowledgments: This work was supported by the National Natural Science Foundation of China (31770618) and the Fundamental Research Funds for Central Universities (2572017AB11).

Author Contributions: Lijuan Wang and Tieqiang Liang conceived and designed the experiments; Tieqiang Liang performed the experiments; Lijuan Wang and Tieqiang Liang analyzed the data; Tieqiang Liang wrote the paper and Lijuan Wang proofread the technical content.

Conflicts of Interest: The authors declare no conflict of interest.

\section{References}

1. Phan, T.D.; Debeaufort, F.; Luu, D.; Voilley, A. Functional properties of edible agar-based and starch-based films for food quality preservation. J. Agric. Food Chem. 2005, 53, 973-981. [CrossRef] [PubMed]

2. Yoshida, C.M.P.; Maciel, V.B.V.; Mendonça, M.E.D.; Franco, T.T. Chitosan biobased and intelligent films: Monitoring pH variations. LWT-Food Sci. Technol. 2014, 55, 83-89. [CrossRef]

3. Maciel, V.B.V.; Yoshida, C.M.P.; Franco, T.T. Chitosan/pectin polyelectrolyte complex as a $\mathrm{pH}$ indicator. Carbohydr. Polym. 2015, 132, 537-545. [CrossRef] [PubMed]

4. Rindlav-Westling, Å.; Gatenholm, P. Surface composition and morphology of starch, amylose, and amylopectin films. Biomacromolecules 2003, 4, 166-172. [CrossRef] [PubMed]

5. Antoniou, J.; Liu, F.; Majeed, H.; Zhong, F. Characterization of tara gum edible films incorporated with bulk chitosan and chitosan nanoparticles: A comparative study. Food Hydrocoll. 2015, 44, 309-319. [CrossRef]

6. Ma, Q.Y.; Wang, L.J. Preparation of a visual $\mathrm{pH}$-sensing film based on tara gum incorporating cellulose and extracts from grape skins. Sens. Actuators B Chem. 2016, 235, 401-407. [CrossRef]

7. Kaur, H.; Yadav, S.; Ahuja, M.; Dilbaghi, N. Synthesis, characterization and evaluation of thiolated tamarind seed polysaccharide as a mucoadhesive polymer. Carbohydr. Polym. 2012, 90, 1543-1549. [CrossRef] [PubMed] 
8. Nayak, A.K.; Pal, D.; Santra, K. Tamarind seed polysaccharide-gellan mucoadhesive beads for controlled release of metformin HCl. Carbohydr. Polym. 2014, 103, 154-163. [CrossRef] [PubMed]

9. Sumathi, S.; Ray, A.R. Release behaviour of drugs from tamarind seed polysaccharide tablets. J. Pharm. Pharm. Sci. 2002, 5, 12-18. [PubMed]

10. Aboshosha, M.H.; Ibrahim, N.A.; Allam, E.; Elzairy, E. Preparation and characterization of polyacrylic acid/karaya gum and polyacrylic acid/tamarind seed gum adducts and utilization in textile printing. Carbohydr. Polym. 2008, 74, 241-249. [CrossRef]

11. Gupta, B.D.; Sharma, S. A long-range fiber optic $\mathrm{pH}$ sensor prepared by dye doped sol-gel immobilization technique. Opt. Commun. 1998, 154, 282-284. [CrossRef]

12. Golasz, L.B.; Silva, J.D.; Silva, S.B.D. Film with anthocyanins as an indicator of chilled pork deterioration. Food Sci. Technol. 2013, 33, 155-162. [CrossRef]

13. Kato, E.T., Jr.; Yoshida, C.M.; Reis, A.B.; Melo, I.S.; Franco, T.T. Fast detection of hydrogen sulfide using a biodegradable colorimetric indicator system. Polym. Int. 2011, 60, 951-956. [CrossRef]

14. Maciel, V.B.V.; Yoshida, C.M.P.; Franco, T.T. Development of a prototype of a colourimetric temperature indicator for monitoring food quality. J. Food Eng. 2012, 111, 21-27. [CrossRef]

15. Makote, R.; Collinson, M.M. Organically modified silicate films for stable pH sensor. Anal. Chim. Acta 1999, 394, 195-200. [CrossRef]

16. Andreou, V.G.; Clonis, Y.D. A portable fiber-optic pesticide biosensor based on immobilized cholinesterase and sol-gel entrapped bromcresol purple for in-field use. Biosens. Bioelectron. 2002, 17, 61-69. [CrossRef]

17. Dong, S.; Luo, M.; Peng, G.; Cheng, W. Broad range pH sensor based on sol-gel entrapped indicators on fibre optic. Sens. Actuators B Chem. 2008, 129, 94-98. [CrossRef]

18. Srivastava, S.; Sinha, R.; Roy, D. Toxicological effects of malachite green. Aquat. Toxicol. 2004, 66, 319-329. [CrossRef] [PubMed]

19. Pávai, M.; Mihály, J.; Paszternák, A. pH and $\mathrm{CO}_{2}$ sensing by curcumin-coloured cellophane test strip. Food Anal. Meth. 2015, 8, 2243-2249. [CrossRef]

20. Choi, I.; Lee, J.Y.; Lacroix, M.; Han, J. Intelligent $\mathrm{pH}$ indicator film composed of agar/potato starch and anthocyanin extracts from purple sweet potato. Food Chem. 2017, 218, 122-128. [CrossRef] [PubMed]

21. Zhang, X.; Lu, S.; Chen, X. A visual $\mathrm{pH}$ sensing film using natural dyes from bauhinia blakeana dunn. Sens. Actuators B Chem. 2014, 198, 268-273. [CrossRef]

22. Beecken, H.; Gottschalk, E.M.; Gizycki, V.U.; Krämer, H.; Maassen, D.; Matthies, H.G.; Musso, H.; Rathjen, C.; Zdhorszky, U. Orcein and litmus. Biotech. Histochem. 2003, 78, 289-302. [CrossRef] [PubMed]

23. National Pharmacopoeia Committee. Pharmacopoeia of People's Republic of China, 2010 ed.; Chinese Pharmacopoeia Commission: Beijing, China, 2010.

24. Kiruthika, A.V.; Priyadarzini, T.R.K. Preparation, properties and application of tamarind seed gum reinforced banana fibre composite materials. Fiber. Polym. 2012, 13, 51-56. [CrossRef]

25. Wang, H.X.; Hu, D.Y.; Ma, Q.Y.; Wang, L.J. Physical and antioxidant properties of flexible soy protein isolate films by incorporating chestnut (castanea mollissima) bur extracts. LWT-Food Sci. Technol. 2016, 71, 33-39. [CrossRef]

26. Lakade, A.J.; Sundar, K.; Shetty, P.H. Nanomaterial-based sensor for the detection of milk spoilage. LWT-Food Sci. Technol. 2017, 75, 702-709. [CrossRef]

27. Zhao, Y.B.; Zhu, L.P.; Chen, J.S.; Ma, D.G. Improving color stability of blue/orange complementary white oleds by using single-host double-emissive layer structure: Comprehensive experimental investigation into the device working mechanism. Org. Electron. 2012, 13, 1340-1348. [CrossRef]

28. Musso, H.; Rathjen, C. Orcein dyes. X. Light absorption and chromophore of litmus. Chem. Ber. 1959, 92, 751-753. [CrossRef]

29. Musso, H.; Beecken, H. Orcein pigments. XII. Syntheses of $\alpha$-hydroxyorcein. Chem. Ber. 1961, 94, 585-600. [CrossRef]

30. Arrais, A.; Diana, E.; Gervasio, G.; Gobetto, R.; Marabello, D.; Stanghellini, P.L. Synthesis, structural and spectroscopic characterization of four $\left[\left(\eta^{6}-p a h\right) c r(C O)_{3}\right]$ complexes (pah = pyrene, perylene, chrysene, 1,2-benzanthracene). Eur. J. Inorg. Chem. 2004, 1505-1513. [CrossRef]

31. Stanghellini, P.L.; Diana, E.; Arrais, A.; Rossin, A.; Kettle, S.F. Benzene and tropilium metal complexes. Intra-and intermolecular interaction evidenced by vibrational analysis: The blue-shift hydrogen bond. Organometallics 2006, 25, 5024-5030. [CrossRef] 
32. Hong, J.; Chen, R.J.; Zeng, X.A.; Han, Z. Effect of pulsed electric fields assisted acetylation on morphological, structural and functional characteristics of potato starch. Food Chem. 2015, 192, 15-24. [CrossRef] [PubMed]

33. Mohan, C.C.; Rakhavan, K.R.; Sudharsan, K.; Krishnan, K.R.; Babuskin, S.; Sukumar, M. Design and characterization of spice fused tamarind starch edible packaging films. LWT-Food Sci. Technol. 2016, 68, 642-652. [CrossRef]

34. Priyadarshini, R.; Nandi, G.; Changder, A.; Chowdhury, S.; Chakraborty, S.; Ghosh, L.K. Gastroretentive extended release of metformin from methacrylamide-g-gellan and tamarind seed gum composite matrix. Carbohydr. Polym. 2016, 137, 100-110. [CrossRef] [PubMed]

35. Nayak, A.K.; Pal, D.; Hasnain, S.M. Development, optimization and in vitro-in vivo evaluation of pioglitazone-loaded jackfruit seed starch-alginate beads. Curr. Drug Deliv. 2013, 10, 608-619. [CrossRef] [PubMed]

36. Elhefian, E.A.; Nasef, M.M.; Yahaya, A.H. Preparation and characterization of chitosan/agar blended films: Part 1. chemical structure and morphology. E-J. Chem. 2012, 9, 1431-1439. [CrossRef]

(C) 2017 by the authors. Licensee MDPI, Basel, Switzerland. This article is an open access article distributed under the terms and conditions of the Creative Commons Attribution (CC BY) license (http://creativecommons.org/licenses/by/4.0/). 